\title{
EL MOVIMIENTO ZAPATISTA ¿UNA POSIBILIDAD DE TRÁNSITO DEL AUTORITARISMO A LA DEMOCRACIA?
}

\author{
Guillermo Puente Ordórica*
}

Luego de cuatro años de conflicto, de una paz tensa y armada, no ha sido posible llegar a una solución definitiva del conflicto chiapaneco. Las negociaciones se han roto en reiteradas ocasiones y los avances parecieran no ser suficientes a pesar de la firma de los Acuerdos de San Andrés Larraínzar en febrero de 1996. La situación de los directamente afectados: los indígenas, no ha sido objeto de cambios sustanciales.

Cuando más cercana parecía estar la solución con la firma de los Acuerdos de San Andrés, el Ejecutivo federal mexicano demoró cerca de dos años en dar su opinión sobre los textos que habían sido acordados. ¿Qué nos queda esperar, la radicalización de las partes, la reanudación de las hostilidades y derramamiento de sangre?, ¿la prolongación ad infinitum del conflicto sin ninguna solución efectiva?

A partir de esas interrogantes este trabajo pretende demostrar las siguientes hipótesis: si bien es importante reconocer los errores y los excesos en que han incurrido los principales actores involucrados en el conflicto: el Ejército $\mathrm{Za}$ patista de Liberación Nacional (EZLN), el gobierno y la iglesia, sostengo, en primer lugar, que el conflicto no ha podido ser solucionado en virtud de que la actual estructura del sistema político no tiene la capacidad de incorporar las demandas de un movimiento peculiar, a la vez tradicional y moderno (algunos lo han calificado de postmoderno), que toca las fibras neurálgicas del propio sistema político, aún autoritario y cerrado. Esa naturaleza peculiar del EZLN se nutre de varias vertientes: la guerrilla tradicional, las ancestrales demandas indígenas y campesinas por su derecho a la tierra, el debate sobre los problemas relacionados con la democracia y el cambio político, la globalización y las identidades culturales, el desarrollo y la pluralidad. Ello permea las vacilaciones y las reticencias del gobierno con respecto al EZLN, así como la aparente indefinición de los insurgentes. Evidentemente, los cauces tradicionales de cooptación del Estado mexicano no han funcionado con la efectividad del pasado, pues el problema no puede tampoco reducirse a ello.

En segundo lugar, es mi propósito sugerir que si el Estado mexicano aprovechara la oportunidad que el movimiento zapatista le brinda para renovarse, en varios sentidos se daría el paso definitivo hacia una transición política que facilitaría la construcción de una democracia genuina sobre bases de pluralidad, por un lado, y la incorporación efectiva de los indígenas al desarrollo nacional, por el otro, sin que ello pudiera significar abandonar los esfuerzos de modernización política y económica del país. Por el contrario, la sociedad y la cultura nacionales se verían alentadas en sus capacidades creadoras a partir del reconocimiento de los grupos e individuos que aportan la vertiente más rica y diversa de las mismas, en beneficio de la credibilidad y la confianza en el sistema político mexicano por parte de sus integrantes: individuos, grupos, comunidades, organizaciones y partidos políticos.

Cabe aclarar que no me refiero a la falta de voluntad política del gobierno por resolver el problema. De hecho pueden contarse como aciertos del gobierno el haber escuchado los reclamos de la sociedad y decidir el cese al fuego y sentarse en la mesa de negociación. Sin embargo, subrayo que la estructura misma del Estado mexicano no tiene la capacidad de incorporar un movimiento como el que el EZLN representa y que existen sectores dentro del gobierno interesados en no propiciar ningún cambio en ese sentido. De tal manera, la voluntad negociadora del gobierno ha desembocado en una suerte de voluntarismo efectista que no ha resuelto, ni resolvería el problema de fondo. La actitud del gobierno mexicano ha sido vacilante y a la vez de sentarse a negociar, ha intentado la vía del desprestigio del EZLN ante la opinión pública, sin que haya tenido el éxito que quisiera.

Finalmente, podría decirse que la apuesta por el desgaste del EZLN mediante la prolongación indefinida de las negociaciones, además de perniciosa dará lugar al surgimiento de mayores problemas, como la violencia por otros cauces. En efecto, la prolongación de una solución integral y de fondo no haría sino favorecer el agudizamiento de las prácticas -ilegales, por supuesto- de los grupos paramilitares, las guardias blancas y la polarización de los pueblos indígenas de la región. Así, privilegiar la vía de la negociación no basta sino se le acompaña de una decisión política de fondo que tenga como objetivo la solución del conflicto y que permita la renovación del sistema político mexicano.

Instituto Universitario Ortega y Gasset. 


\section{La estrategia gubernamental}

El 1 de enero de 1994, irrumpieron en la escena nacional los insurgentes organizados en torno al Ejército Zapatista de Liberación Nacional, ocupando varias ciudades y pueblos de Chiapas. El México imaginario que se alistaba ese día a ingresar al primer mundo, sufrió un fuerte revés del México profundo. Tras unos días de enfrentamiento entre el EZLN y el ejército federal, el gobierno decidió unilateralmente un cese al fuego.

La decisión del gobierno de México aunque sorpresiva para muchos se basaba en fuertes determinantes en ese sentido. Tomemos en consideración que el ejército mexicano se había enfrentado a la guerrilla el 22 de mayo de 1993 y el día 24 descubría en la sierra de Corralchén un campamento del EZLN (Las Calabazas) concebido para más de 200 combatientes y sin embargo el gobierno no tomó ninguna acción en consecuencia, según lo describe el historiador Carlos Tello. ¿Cómo explicar entonces el contradictorio actuar del gobierno mexicano? Para Montemayor, entre otras razones, el entonces presidente Salinas se resistía a creer que se preparara una insurrección en esa región de Chiapas. Asimismo, la percepción en los altos círculos gubernamentales, incluyendo al secretario de gobernación González Garrido, pareció girar en torno a la visión de que detrás de las acciones guerrilleras se hallaban los catequistas y sacerdotes de la diócesis de San Cristóbal. Por lo tanto, el gobierno presionó para que el obispo Samuel Ruíz fuera removido por el Vaticano. Un segundo elemento para guardar el silencio y no actuar, fue la carrera por la sucesión presidencial, que en ese momento tenía a Fernando Gutiérrez Barrios como protagonista principal, aunque el motivo más poderoso que obligaba a dejar de lado

la alarma roja provino de Estados Unidos: la acalorada polémica parlamentaria en torno a la aprobación del Tratado de Libre Comercio. El gabinete económico del presidente sabía que la firma de ese tratado habría sufrido graves tropiezos si se hubiera hecho pública la existencia de una nueva guerrilla, que revelaría un México con fisuras sociales y económicas. El gabinete de Salinas quería mostrar un México moderno... la esperanza de su firma propició que el gobierno de Salinas de Gortari desestimara la luz de alarma que se había encendido en las Cañadas chiapanecas. (Montemayor, 1997: 33).

En su primer manifiesto denominado Declaración de la Selva Lacandona, el EZLN para dar legitimidad a la insurgencia apelaba a las leyes nacionales. En concreto al artículo 39 de la Constitución, para suplantar a "la dictadura de más de 70 años... monopolizada por el partido en el poder y encabezada por el ejecutivo federal que hoy detenta su jefe máximo e ilegítimo, Carlos Salinas de Gortari... Nuestra lucha se apega al derecho constitucional y es abanderada por la justicia y la igualdad...", pedían a los poderes Legislativo y Judicial que restablecieran la legalidad deponiendo al dictador y declaraban su intención de observar la Convención de Ginebra. Finalmente, el EZLN exigía el cumplimiento de 10 demandas centrales: trabajo, tierra, techo, alimentación, salud, educación, independencia, libertad, democracia, justicia y paz. (Primera Declaración de la Selva Lacandona, 1994: 1).

¿Cómo combatir una guerrilla que apela al marco constitucional, que no se pronuncia por la toma del poder y que reivindica demandas asequibles tanto a los indígenas como al grueso de la población? La primera reacción oficial fue desviar la atención pública hacia causas artificiales. "El gobierno federal argumentó con lúcida lógica que la pobreza no podía ser una causa de la insurrección porque tanta pobreza o más se padecía en otras regiones del país y no había surgido en ellos un EZLN." (Montemayor, 1997: 42-50) No obstante, la irrupción del EZLN inició el proceso de desmoronamiento de la imagen que Carlos Salinas de Gortari se había propuesto construir para su régimen, es decir, de modernización y de estabilidad política, económica y social. Baste recordar que a finales de 1993, había declarado a una prestigiosa publicación internacional, que México se aprestaba a ingresar al primer mundo, en una de las elaboraciones discursivas que seguramente pueden ser consideradas como pieza maestra de la demagogia de la clase política mexicana de fines del siglo XX. Así las cosas, el día 6 de enero, el presidente dirigió un mensaje a la nación en la que expresaba que

una organización diferente emergió en el estado de Chiapas. Profesionales de la violencia, nacionales y un grupo extranjero, ajenos a los esfuerzos de la sociedad chiapaneca, asestaron un doloroso golpe a una zona de Chiapas y al corazón de todos los mexicanos. Por eso, se ha señalado con razón que deben distinguirse claramente dos situaciones: una, la agresión armada de un grupo violento, y otra muy diferente, la que deriva de la situación de pobreza y carencias en esa región. Este no es un alzamiento indígena, sino la acción de un grupo violento, armado, en contra de la tranquilidad de las comunidades la paz pública y las instituciones de gobierno..." (Montemayor, 1997: 54).

El día 10 de enero, Salinas hizo cambios en su gabinete y nombró a Manuel Camacho Solís como Comisionado para la Paz y la Reconciliación en Chiapas. El día 12 de ese mes, el gobierno decretó la suspensión unilateral de las hostilidades en Chiapas. En todo ese trance debe tenerse presente la reacción generalizada de la sociedad y la opinión pública que hicieron un llamado por la paz y la condena de la solución militar. Ambos elementos marcaron sin duda el rumbo político y militar que tomaría el conflicto. El EZLN se convertía en una fuerza militar y política.

La decisión del gobierno, si bien obligada por las circunstancias, fue sin duda un acierto en el corto plazo, pues al optar por la vía de la no violencia y la negociación evitaba el desgaste y el costo político y aparecía como consecuente con los reclamos de la sociedad mexicana que mayoritariamente se opuso a la represión. No en vano dicha decisión sorprendió al propio EZLN. Empero, cabría reflexionar si desde la lógica del poder, dicha decisión no fue un error político en el largo plazo, en la medida que el gobierno mismo se maniataba las manos para 
proceder frontalmente contra un "grupo de insurrectos". Lo anterior surge como duda toda vez que la decisión gubernamental se basó no en el entendimiento del movimiento zapatista, su naturaleza y causas, sino en la necesidad de evitar mayores consecuencias políticas y sociales para el propio régimen y sobre todo para prevenir un desprestigio de la imagen internacional del presidente mexicano, que tantos millones de dólares había costado construir. En efecto, "cualquier conflicto armado provoca una demostración oficial inmediata y una represión no menos vertiginosa. La descalificación es la primer arma que se esgrime contra un levantamiento popular, urbano, campesino o indígena; la segunda arma es la policiaca o la militar. Y se descalifica negando, o intentando negar, su naturaleza, sus causas, su magnitud o su profundidad social." (Montemayor, 1997: 54)

Es importante mencionar que la actitud adoptada desde un principio por el gobierno mexicano no ha variado en la sustancia hasta el momento, puesto que a lo largo de estos años se ha querido reducir el levantamiento zapatista a una manipulación de un sector de la población indígena por parte de actores no indígenas. En varios momentos se ha querido identificar al EZLN con el levantamiento de algunas comunidades tradicionales, retrasadas, manipulables y manipuladas por guerrilleros anacrónicos o bien por ideólogos y fuerzas interesadas en hundir a México en la violencia y en hacer fracasar su entrada en el mercado internacional, la democracia y la modernidad. "Los intentos oficiales por descalificar políticamente al EZLN con base en los antecedentes de las Fuerzas de Liberación Nacional, surgidas en el norte del país, no hacen sino revelar las profundas y complejas raíces que el EZLN hunde en los treinta años de continuidad de lucha guerrillera en México." (Montemayor, 1997: 69).

Sin entrar a hacer un balance detallado del trabajo desarrollado por parte de algunos de los varios negociadores que el gobierno federal ha nombrado, pues escaparía al objetivo principal de este ensayo, la evaluación que ellos mismos hacen de su labor parece evidenciar lo señalado anteriormente $y$, fundamentalmente, que no existe una línea clara de lo que el gobierno debía hacer para solucionar la situación. Por ejemplo, el que fuera el primer negociador gubernamental, Manuel Camacho Solís (quien no es más un hombre del sistema pues rompió años después con el Partido Revolucionario Institucional [PRI] para crear un nuevo partido político), apunta que debe repensarse una estrategia de Estado y no sólo de gobierno, en la medida de que se trata de construir un Estado de derecho en donde nunca ha existido para entender qué está pasando y tener posibilidades de éxito. (Camacho Solís, 1998: 5-6).

Por su parte, Marco Antonio Bernal, quien durante su desempeño logró la firma de los Acuerdos de San Andrés Larraínzar, subraya que el EZLN se ha negado a dialogar en este tiempo y ha hecho pronunciamientos y acusaciones sin fundamento. En esa medida, indica, que hacen falta propuestas políticas como la aplicación de la ley y la justicia así como una política social de largo alcance en la zona y voluntad de negociación no sólo del gobierno..."Lo repito y lo reitero: falta voluntad política del EZLN y de otros actores chiapanecos que deben manifestar su voluntad de llegar a un acuerdo de paz [y señala que] los Acuerdos de San Andrés no tienen absolutamente nada que no pueda ser traducido jurídicamente si se hace con ponderación y con un sentido de unidad nacional." (Bernal, 1998: 7).

Finalmente, Pedro Joaquín Coldwell anota que "aunque parezca paradójico, la extrema gravedad del conflicto chiapaneco puede propiciar también la coyuntura para que los márgenes de negociación se amplíen" y que para ello se requiere que los interlocutores dejen la cerrazón, la insensatez y la soberbia, para que el negociador pueda avanzar en la paz e impedir que los acontecimientos sigan rebasando a las instituciones. (Coldwell, 1998: 5).

Si la negociación es el camino aceptado, cabe preguntarse entonces ¿qué tipo de negociación? Parecería que el rumbo es el de negociar "golpeando", en la medida en que no existe una unanimidad de criterios dentro del gobierno de cómo afrontar el problema, y más grave aún, que existen algunos sectores que apuestan por el desgaste de la guerrilla y la violencia diseminada por otros cauces que no provengan directamente del gobierno, es decir, de los grupos paramilitares surgidos en la ilegalidad y con nexos aparentemente no identificables a ninguna institución u organización política, con el propósito de desarticular progresivamente a la insurrección. No obstante, se han logrado identificar 12 organizaciones de este tipo en Chiapas, que presuntamente tienen nexos con el PRI. (Enfoque/Reforma, 1998: 6).

La apuesta es peligrosa pues la situación podría vol verse incontrolable. Lo anterior sin mencionar que ante la amenaza de la violencia generalizada en la región, se darían las condiciones necesarias para proceder en consecuencia. Los resultados no son imprevisibles en ese escenario donde se aplicaría toda la fuerza de la ley sobre los delincuentes y los infractores del estado de derecho.

\section{Antecedentes del surgimiento del EZLN}

El EZLN surge a partir de la imbricada red de relaciones políticas, religiosas, económicas, sociales y culturales de Chiapas. En ella concurren actores diversos, los indígenas, por supuesto, pero actores externos como la iglesia, los grupos guerrilleros (principalmente las Fuerzas de Liberación Nacional), las organizaciones políticas de distintas orientaciones, los gobiernos federal y estatal, etc.

De tal suerte, los antecedentes deben buscarse, por un lado, en los procesos ancestrales de la lucha indígena y campesina por la tierra, pero también en la lucha guerrillera que comienza en México alrededor de 1965, en el activismo de la iglesia cercana a la teología de la liberación en esa región, en el recrudecimiento de la represión gubernamental a partir de los años setenta y ochenta y en la acentuación de los conflictos como consecuencia de las reformas emprendidas por la administración salinista.

Conviene tener presente que la pobreza y marginación de los pueblos indígenas chiapanecos no es nueva como tampoco lo es la represión de la que han sido objeto. Carlos Tello indica que los indígenas que trabajaban en las fincas 
de Chiapas eran descendientes de los pueblos más notables del antiguo México ${ }^{1}$.

Hasta el siglo VI, la región vivió bajo la influencia de la cultura maya, y más tarde, hasta el siglo XV, bajo el predominio de la migración tolteca. Con el paso de los años fue sojuzgada por los aztecas, que convirtieron a sus pobladores en tributarios de $\mathrm{Te}$ nochtitlán. La región, a pesar de todo, permaneció dueña de sus costumbres hasta la llegada de los españoles en el siglo XVI. Los conquistadores arrasaron por completo con la vida de las comunidades. Los indios fueron diezmados por las epidemias, las guerras, las hambrunas y las deportaciones. Más del 75 por ciento murió durante las primeras décadas de la Conquista. Pueblos enteros desaparecieron de la geografía y de la historia entre 1524 y $1544 \ldots$ Ese terrible periodo -ese katún-acabó con la llegada de los dominicos a la provincia de Chiapas. 'Fueron ellos quienes establecieron las bases de un sistema de vida que para la población india permanecería vigente hasta mediados del siglo XIX'. Y también ellos habían sido los propietarios de las fincas más grandes durante la Colonia, ya que 'los frailes no siempre mantuvieron aquella actitud inicial de defensores de los indios'. (Tello, 1995: 32),

Empero, las leyes de reforma terminaron con el predominio de los dominicos, quienes en 1858 , tuvieron que dejar todos sus bienes para salir al exilio en Guatemala. Sus propiedades fueron adquiridas por familias -los Albores, los Domínguez, los Castellanos- que todavía las conservaban a mediados del siglo XX, a pesar de la retórica de la Revolución, la cual nunca triunfó en Chiapas. Esas familias junto con la tierra, heredaron cientos de indígenas que trabajaban en las fincas.

Si bien el nivel de vida de los mestizos, apunta Tello, tomando como ejemplo la finca de El Porvenir en Ocosingo, propiedad de Javier Albores, era muy bajo, era también muy superior al de los indígenas. Su dominio lo cimentaban en el monopolio que tenían sobre la tierra. La sobreexplotación de los acasillados, que permitía ese monopolio, fue la base de su modelo de acumulación de capital. Durante la Revolución los finqueros organizaron ejércitos, secundados por sus peones, para combatir a los constitucionalistas a quienes derrotaron tras seis años de lucha y más adelante pactarían con Obregón el respeto de sus privilegios. En la década de los cincuenta, los finqueros del estado detentaban aún el 70 por ciento de las tierras.

$\mathrm{Al}$ describir las condiciones de los peones y sus familias, que vivían en El Porvenir, no obstante su buena relación con el patrón, Tello subraya que “...parecían extraviados. Sin tierra, sin derechos, sin nada, estaban a disposición de lo que dijeran los patrones. Vivían al margen del Estado, fuera de la Revolución. También vivían olvidados por la Iglesia." Cabe destacar que el poder de los finqueros no se basaba únicamente en la coerción, los peones, al aceptar la supremacía de los finqueros, le conferían una especie de legitimidad al ejercicio de su poder. No obstante, los indígenas que trabajaban para los finqueros de los valles, en medio de su desamparo, permanecían integrados al interior de su comunidad. Ello les permitió reproducir el espacio social que necesitaban para conservar sus tradiciones.

La vida de los acasillados no tenía perspectivas de mejorar en el ámbito de El Porvenir...su situación era la misma que la de todos los indígenas que laboraban en las fincas de los valles de Ocosingo. Estaban hartos, ésa era la verdad.. Había que trabajar de sol a sol... La gente ya estaba cansada de tener patrón ¿Por qué razón, entonces, soportaban esa rutina? ¿Por qué vivían ahí, acasillados en las fincas?... La realidad, más bien, era que no tenían ningún otro lugar para residir en paz. Los indígenas de la región habían perdido sus tierras a lo largo de la Colonia. Al principio las perdieron con la fuerza de las armas en beneficio de los blancos -o los caxlanes, como decían ellos. Más tarde las volvieron a perder ante la codicia de los dominicos, que los convirtieron a todos en los tributarios del Señor. Los pocos que las conservaron, reconocidos como pueblos, fueron con los años afectados por las leyes de desamortización que proclamaron los liberales de Benito Juárez. Sus tierras, puestas a la venta junto con las de los dominicos, las compraron los finqueros del estado, aunque muchos, claro, ni siquiera las tuvieron que comprar: simplemente las robaron. La historia del saqueo de las comunidades, obra de la violencia de las armas y de las leyes, explicaba la dependencia de los indígenas respecto de las fincas que lindaban con la Selva (Tello, 1995: 41-42).

Más adelante los cambios en el patrón de producción, esto es, que del cultivo de café se pasó a la ganadería, tendrían serias consecuencias para los peones ya que su trabajo estaba concentrado en la tarea de cuidar los cafetales. El incremento de los potreros, a costa de los cafetales, disminuyó de golpe la demanda de las fincas por la mano de obra de los peones. Pero además las tierras que los patrones les permitían usufructuar para el autoconsumo se volvieron por ese cambio, en una necesidad para el ganado. Ante esa situación, el gobierno federal favoreció la emigración hacia la selva, como una válvula de escape para controlar la presión de los indígenas sobre la tierra de las fincas de Ocosingo. "Por esos años empezaban a surgir una serie de comunidades, organizadas en ejidos [Suchilá, Las Delicias, San Miguel y Laguna del Carmen Pataté, entre otros], que poblaron la región más alta de las Cañadas." (Tello, 1995: 44).

1. En su libro La rebelión de las Cañadas, Carlos Tello ofrece un recuento histórico de los orígenes de la situación social, económica y política actual en Chiapas, el cual es un trabajo serio e interesante en esa parte y no así en los capítulos en donde aborda el surgimiento propiamente del EZLN, los cuales están llenos de imprecisiones y afirmaciones falsas. Dicho lo anterior, deseo subrayar que he considerado conveniente elaborar este inciso del trabajo a partir de dicha investigación, en lo concerniente a los antecedentes. Es así que con el fin de evitar inundar con notas bibiliográficas y permitir una lectura más ágil, debe tenerse en mente que la información pertenece a dicho estudio y sólo se hacen notas cuando se trata de pasajes idénticos y/o extensos o bien de otras fuentes distintas a las de ese autor. 
Además de los indígenas que llegaron a la Selva Lacandona provenientes de Ocosingo, por diversas razones arribaron, asimismo, choles del Norte, tzotziles de los Altos, tojolabales de los Llanos, zoques de los Valles Centrales de Chiapas. La Selva fue poblada por los habitantes más empobrecidos del estado de Chiapas. Empero, no fueron los indígenas chiapanecos los únicos en salir hacia la tierra prometida ya que hacia esa región concurrirían campesinos provenientes de otros estados como Tabasco, Oaxaca, Veracruz, Puebla y el D.F., es decir, más diversidad dentro de la diversidad: náhuas, mixes, totonacos, chontales, etc.

Sin embargo, en ese éxodo a la tierra prometida la iglesia decidió acompañar y guiar a los indígenas (dando contenido "real" a los pasajes bíbilicos del éxodo). En especial los misioneros de la orden de Predicadores fueron quienes le dieron un sentido místico-religioso a su marcha.

La Iglesia fue, por su presencia, el ordenador más importante de las comunidades que salieron a poblar la Selva. A mediados de la década de los sesenta, las comunidades comenzaron a enviar a la diócesis de San Cristóbal de Las Casas, a algunos de sus miembros para que fueran catequizados y pudieran después, llevar la palabra de dios a sus propias comunidades. Con base en el prestigio que tenían en su comunidad y el contacto que mantenían con el mundo de los caxlanes, estos individuos con el paso de los años serían los dirigentes de las organizaciones que surgieron en la Selva.

"Bajo la influencia combinada del aggiomamiento en el seno de la iglesia (1962: Concilio Vaticano II; 1968 : Conferencia Episcopal Latinoamericana de Medellín, Colombia) y las demandas de la población, se generó, hacia finales de los sesenta, una variante en el seno de la cual algunos catequistas discutieron la orientación esencialmente pastoral de la acción misionaria... 'Si la iglesia no se hace tzeltal, no es católica'.” (Le Bot, 1997: 45) El personaje clave de este cambio fue monseñor Samuel Ruiz, obispo de San Cristóbal desde 1960, quien optó por la "opción preferencial por los pobres” de la teología de la liberación.

En Chiapas [la diócesis]... se ha distinguido por una fuerte voluntad de indianización. La 'inculturación’, término que a veces emplean los eclesiásticos, designa las formas más sistemáticas del proyecto para fundir al cristianismo en el molde de las culturas autóctonas... El Congreso Indígena de 1974, bajo la égida del obispado, cristalizó esa reorientación del movimiento de recristianización, pero marcó también el principio de un nuevo centro de influencia al consagrar el papel central de la diócesis en el proceso de cambio. Sin embargo, el movimiento indígena ganó, a partir de ese momento, en diversidad y complejidad, y se transformó en objeto de disputa de diferentes fuerzas políticas y sociales (Le Bot, 1997: 47).

Las conversiones religiosas y las luchas sociales son elementos indispensables para la comprensión de la génesis del zapatismo. La orientación de la iglesia católica se explica, igualmente, por la evolución a la que ella misma contribuye en el seno de la población indígena, pero también por la competencia que le representan las iglesias evangélicas (protestantismo histórico, y sobre todo pentecostés) y milenarias (adventista, Testigos de Jehová, iglesia mormona). Entre estas iglesias y el catolicismo renovado son tantas las similitudes sociológicas como las tensiones y las contraposiciones. No obstante, la conversión al neocatolicismo o a cualquiera de las nuevas iglesias significa una ruptura con la comunidad tradicional y con el antiguo sistema de cargos, ya sea de comunidades católicas homogéneas, de grupos evangélicos o de sectas, en la medida en que la tendencia a sustituir el antiguo comunitarismo por uno nuevo es muy fuerte. Tanto en unas como en otras, la 'visión teológica de la realidad' y la lucha contra un medio natural hostil y contra las agresiones perpetradas por los enemigos de la comunidad, alimentan conductas de defensa y repliegue. (Le Bot, 1997: 49).

A partir de los años sesenta, la historia estaría impregnada de errores burocráticos de las autoridades estatales y federales, por el activismo de la iglesia y la organización política indígena y campesina, así como por la penetración en la zona de grupos guerrilleros. Ahora bien, el 6 de marzo de 1972 un decreto del entonces presidente Luis Echeverría, marcaría una fecha importante en el catálogo de errores y contradicciones del gobierno. Ese decreto que quiso ser, ante la opinión pública, un acto de justicia que devolvía la posesión de todas esas tierras a los lacandones, en realidad beneficia a la institución financiera-gubernamental denominada Nacional Financiera (Nafinsa) para "impulsar" el negocio maderero. La tala sería más o menos del orden de diez mil árboles al año, entre cedros y caobas. En efecto, con ese decreto, el gobierno federal titulaba 614 321 hectáreas a sesenta y seis familias de la tribu de los lacandones (9 307 hectáreas a cada jefe de familia).

La retórica populista, además de que no benefició a los que pretendía favorecer, negó el derecho sobre la tierra que tenían más de cuatro mil familias, choles y tzeltales, que vivían en el mismo territorio recuperado: Treinta y siete familias fueron amenazadas de golpe con ser desalojados, a pesar de tener la posesión real de las tierras en que vivían. Las cañadas más afectadas fueron Avellanal, Amador y Agua Azul. En ellas había comunidades muy significativas, como por ejemplo San Francisco, Pichucalco, La Soledad, Ibarra, El Guanal, Amador, Plan de Guadalupe -lo que sería después el corazón del EZLN (Tello, 1995: 59-61).

En ese panorama, la iglesia en Chiapas, y más particularmente la diócesis de San Cristóbal de Las Casas hizo suyas las demandas de las comunidades indígenas y promovió la concientización y la acción políticas. La diócesis promovió la celebración en San Cristóbal del Congreso Indígena de 1974, fecha del 400 aniversario del nacimiento de Bartolomé de las Casas. En este evento surgió la idea de formar una organización para representar los intereses de las comunidades de la Selva que en 1975 cristalizaría en la Quiptic Ta Lecubtesel (en tzeltal Unidos por Nuestra Fuerza). Más adelante, la diócesis entraría en contacto con otra organización que luchaba por el cambio de sistema: Unión del Pueblo, en la que primaban dos tendencias que, con los años, acabarían por dividir la base del movimiento, 
una guevarista y otra maoísta, la cual trabajaría en la región en alianza con la diócesis de San Cristóbal.

Asimismo, en 1976 una organización más entraría en la región chiapaneca a reforzar la labor de concientización del obispo, es decir, "Política Popular" (dividida a su vez en la "Línea de Masas" y "Línea Proletaria" de tendencia maoísta, uno de cuyos dirigentes sería después líder de la CNC del PRI en la administración Salinas). Este activismo no era gratuito, ya que la represión de finales de los sesenta y la aún más cruenta de los setenta había suscitado diversas reacciones en la izquierda: métodos que irían desde la organización política y social hasta la clandestinidad y la violencia.

A lo largo de la década de los setenta, las comunidades de las Cañadas, junto con sus asesores, religiosos y laicos, tuvieron un objetivo común en el seno de la Quiptic: estaban contra la brecha que habría de dividir en dos a la Selva, de acuerdo con el Decreto de la Comunidad Lacandona de 1972. Empero, en 1978 la situación se agravaría en virtud de un nuevo decreto presidencial. El presidente en turno, José López Portillo, firmaba el Decreto de la Reserva Integral de la Biosfera de Montes Azules, que venía a sobreponerse al decreto de Echeverría.

Todos ellos otorgaban miles de hectáreas, las mismas, a propósitos totalmente diferentes. La reserva tenía, en el centro, un núcleo de 249433 hectáreas que, en muchas partes, coincidía con la Comunidad Lacandona (era el caso del cordón del Chaquistero) y también, a veces, con las comunidades de la Selva (era el caso del ejido San Gregorio). Había poblaciones que fueron incluso afectadas por todos los decretos a la vez, como por ejemplo Pichucalco. Con el tiempo, los ejidos, acorralados por estas leyes, empezaron a ser víctimas de la desesperación. (Tello, 1995: 78-79).

Las respuestas de los diversos ejidos a la decisiones oficiales fueron distintas, algunos accedieron a reacomodarse, otros no aceptaron tales medidas, que en el fondo significaba dejar atrás su patrimonio. En 1980, en disputa por las tierras de la Comunidad Lacandona, los ejidos de las Cañadas, encabezados por Quiptic, formaron la Unión de Uniones Ejidales y Grupos Campesinos Solidarios de Chiapas, con base en el municipio de Las Margaritas, aglutinando además de Quiptic a la Unión de Ejidos Tierra y Libertad y la Unión de Ejidos Lucha Campesina, abarcando trece municipios en total, es decir, doce mil familias, ciento ochenta comunidades, todas ellas católicas (Tello, 1995: 80)

A mediados de 1982 el panorama era muy complejo ya que el Congreso Indígena de Chiapas, al promover el encuentro de las comunidades, al facilitar la llegada de los asesores al estado, fue, sin duda, el catalizador más importante de las organizaciones.

También lo fueron, en menor medida, los partidos. Muchos llegaron a lugares, como las Cañadas, en donde no tenía presencia el PRI. "Entre ellos estaban el PMT, el PRT y el PCM...Todos ellos, militantes de partidos, asesores, sacerdotes, ayudaron a modificar el curso de la historia de
Chiapas. Entre ellas destacaban sobre todo dos: la CIOAC [Central Independiente de Obreros Agrícolas y Campesinos] y la OCEZ [Organización Campesina Emiliano Zapata]... La CIOAC y la OCEZ, con otras organizaciones más, habrían de servir después al EZLN para superar el marco de la Unión de Uniones... para crecer hacia fuera de las Cañadas." (Tello, 1995: 80).

\section{La radicalización del movimiento indígena}

Si bien sería excesivo hacer un recuento de los antecedentes inmediatos del surgimiento del EZLN, que por lo demás están documentados en el libro de La Grange y Maite Rico, es importante señalar que en 1983 coincidentemente con la ruptura de la Unión de Uniones, arriban a las Cañadas, quienes más adelante formarían el EZLN. Esos hombres y mujeres (Germán, Rodrigo, Elisa, Marcos, Gabriela, Daniel, Pedro, Lucía, Javier, Eduardo, Manuel y Rodolfo) eran miembros de las Fuerzas de Liberación $\mathrm{Na}$ cional (FLN), fundadas en los sesenta y que se creían desaparecidas por el gobierno.

Sin embargo, para explicar la radicalización del movimiento indígena no basta con saber la existencia de las FLN, la identificación de las verdaderas personalidades de los dirigentes del EZLN y su labor de ideologización, ya que el movimiento tiene su origen y su impulso, asimismo, en las conversiones, las disidencias y las divisiones en el seno de las comunidades. Al mismo tiempo, dichos fenómenos se han reflejado en migraciones intraestatales, luchas sociales y mutaciones culturales. El zapatismo se desarrolló en el seno de sectores de la población indígena que habían sido desplazados y que, en palabras de Le Bot, inventan un nuevo tipo de tradición y que, por esa razón, tuvieron que romper con sus comunidades originales o incluso abandonarlas. En su separación se confunden motivos religiosos, económicos y políticos.

Veamos, en 1985, "cuando la OCEZ decidió invadir varias tierras sobre las cuales sentía tener derecho y la dueña optó por entregarlas a la CNC, esta organización oficialista y el gobierno de Chiapas planearon una estrategia que no podemos considerar de ninguna manera ingenua: crear en el centro de esas comunidades independientes, un nuevo ejido alineado a la $\mathrm{CNC}$, que constituye una clara cuña de agresión y polarización campesina: el Thomas Munzer." (Montemayor: 1997, 35) Las movilizaciones policiacas en los poblados cercanos a ese ejido y el encarcelamiento de 23 sublevados tzeltales a los que se les confiscaron armas como hachas, machetes y serruchos (tres de los rebeldes tenían la edad de 76, 98 y 102 años), evidenciaron la tendencia a fortalecer enclaves de la CNC y a reprimir a las organizaciones campesinas no alineadas al oficialismo.

Paralelamente a los errores burocráticos como vimos en el inciso anterior, la política de represión se acentúo con el paso del tiempo. Al respecto, la gestión del gobernador Absalón Castellanos resulta esclarecedora. Montemayor señala que como gobernador Patrocinio González Garrido (a la postre secretario de gobernación) mantenía un tenso distanciamiento con Samuel Ruíz y consideraba que detrás de las actividades guerrilleras se 
hallaban los catequistas y sacerdotes que trabajaban en la diócesis. Bajo su mandato se aprobó un Código Penal con el cual hasta protestar se volvió un delito. No debe sorprender que una vez como secretario de Gobernación de Salinas de Gortari en 1993, tanto él como el gobernador interino, Elmar Setzer, desestimaran la fuerza del EZLN, así como tampoco resulta extraño que el gobierno mexicano presionara al nuncio apostólico, Girolamo Prigione, para que la Santa Sede removiera al obispo Ruíz de la diócesis. De hecho, el nombramiento de González Garrido "consumó la polarización extrema de fuerzas en el estado: por un lado, las que intentaban avanzar hacia una modernidad que, con reformas legales, laborales y agrarias, impulsarían a los grandes capitales y a los grandes finqueros; por otro, las comunidades indígenas de las Cañadas y de los Altos, las organizaciones campesinas independientes, la diócesis de San Cristóbal y, hasta ese momento como un secreto guardado a voces, el EZLN" (Montemayor, 1997: 102). Conviene repetir que a mediados de 1994, el ejército había descubierto el cuartel de Las Calabazas en la sierra de Corralchén.

Sin embargo, el detonante final estaría vinculado con el llamado proceso de modernización del aparato productivo mexicano para insertarlo en las corrientes de la globalización económica mundial y que tendría graves repercusiones para el campo mexicano. En Chiapas el detonante de la insurgencia sería la reforma del artículo 27 de la Constitución en connivencia con la corrupción política en ese estado. Si bien diversos decretos presidenciales perjudicaron a los campesinos y a los indígenas favoreciendo a los finqueros, ganaderos y madereros, como se vio anteriormente, la lucha por la tierra tras la reforma mencionada parecía terminar beneficiando a los poderosos.

El artículo 27, uno de los baluartes constitucionales de la Revolución Mexicana fue reformado al extremo de su cancelación [del reparto agrario] definitiva. Se aseguró la propiedad privada agraria eliminando las secciones del artículo que permitían a las comunidades solicitar el reparto de tierras y autorizando, además, que las tierras ejidales pudieran legalmente comprarse, venderse o usarse como garantía de créditos, a fin de que las empresas privadas, con nuevas asociaciones entre capitalistas y propietarios, pudieran adquirir tierras ejidales de acuerdo con los nuevos límites legales, dando como resultado que una empresa con accionistas pudiera incrementar 30 veces su propiedad a partir del límite individual. Es decir, se sentaron las bases para legalizar los latifundios familiares o corporativos... El fin de la reforma agraria cancelaba la oportunidad a las comunidades de recibir tierras conforme a la legislación anterior. (Montemayor, 1997: 100).

En efecto, los caciques de los pueblos podrían comprar tierras a los campesinos más pobres, y ello aunado al fin del reparto de tierras, afectaba a las comunidades indígenas chiapanecas en varios sentidos: Chiapas era el estado con mayor rezago agrario, la carencia de títulos definitivos de propiedad aumentaba la posibilidad de desalojo por parte de terratenientes o de asociaciones campesinas oficiales y porque impedía el otorgamiento de créditos.

María Eugenia Reyes Ramos, destaca que los mecanismos oficiales frenaron siempre las demandas de tierra de los campesinos de la Selva: 79 comunidades tuvieron que esperar más de 20 años para que se les entregaran las tierras solicitadas, otras como El Letrero, en Siltepec 53 años, en contraste con la celeridad de las resoluciones favorables a los terratenientes. De 1982 a 1988 se otorgaron en Chiapas 7646 certificados de inafectabilidad que ampararon 1,142,881 hectáreas predominantemente ganaderas. (Reyes Ramos en Montemayor, 1997: 115).

En ese contexto, los cuadros de la guerrilla, quienes desde el principio aprovecharon las redes de la iglesia en la región, lograrán al final hacer prevalecer sus puntos de vista en favor del camino, lo cual sucedería en enero de 1994. Cabe apuntar que no todas las comunidades estaban de acuerdo pero una vez tomada la decisión era imposible dar marcha atrás.

\section{Un mundo en el que quepan varios mundos}

¿Podría explicarse el conflicto chiapaneco como un conflicto entre modernización versus tradición? Para acercarse a la respuesta a esta interrogante es conveniente poner en el centro del análisis a su actor central: el indígena. Si partimos de la base de que los indígenas son sólo individuos manipulados por una organización políticomilitar ajena a las comunidades, por la iglesia o un sector de ella, por fuerzas políticas interesadas en frenar la modernización del país y su ingreso en el gran mercado, incluso por un Marcos que ocultaría su verdadero juego detrás de un lenguaje poético-político y un maniqueísmo de símbolos, o un obispo que no denuncia los excesos del EZLN en función de su interés de ganar el Nobel de la Paz², la insurrección indígena del EZLN se reduce a lo que en varias ocasiones el gobierno ha tratado de difundir: esto es la rebelión de un grupo de profesionales de la violencia.

Además, me parece importante considerar el contexto nacional e internacional en el que se da la aparición del EZLN, esto es, la profundización del denominado modelo económico neoliberal en México, en el marco del fin de guerra fría y la globalización, que nos estaría indicando que no se trata de un movimiento guerrillero ortodoxoclásico (por llamarlo de alguna forma) del pasado, ya sea marxista-leninista, guevarista, etc. y, que por el contrario, nos ayudaría a entender la mutación que sufre el EZLN una vez que abandona el clandestinaje e irrumpe en la escena pública interna y externa. Finalmente, las demandas que la insurrección pone sobre la mesa de discusión son otro elemento de enorme trascendencia: democracia y justicia, entre otras.

Montemayor señala que para entender la relevancia del EZLN, se debe reconocer que la insurrección no se inició el 1 de enero de 1994, sino varias décadas antes.

2. Algunas de esas aseveraciones, francamente exageradas, se hacen en el libro Marcos, la genial impostura, de La Grange Bertrand y Rico Maite (1998), México, Nuevo Siglo Aguilar, 472 p. 
México ha vivido en estado de guerra de manera casi ininterrumpida al menos desde el amanecer del 23 de septiembre de 1965, cuando un grupo de jóvenes guerrilleros quiso tomar por asalto el cuartel militar de Ciudad Madera, población de la sierra de Chihuahua muy cercana a los límites del estado de Sonora... señalo esta fecha por la continuidad de las luchas armadas que vivió el país entero durante los siguientes casi treinta años, aunque en la década de los cincuenta Morelos fue escenario de otro importante movimiento guerrillero encabezado por $\mathrm{Ru}$ bén Jaramillo, movimiento también de raigambre zapatista y de bases campesinas e indígenas... Los movimientos guerrilleros de Genaro Vásquez Rojas y de Lucio Cabañas fueron resultado de la radicalización provocada por la represión del gobierno del estado de Guerrero y las fuerzas caciquiles que asfixiaban las demandas agrarias de la Costa Grande guerrerense y de la sierra de Atoyac [la cual] durante el año de 1995, en las mismas zonas y contra campesinos otra vez inermes, ahora en Aguas Blancas, se ha vuelto a manifestar impunemente. (Montemayor, 1997: 67-68)

De tal suerte, Montemayor distingue dos tipos de movimientos armados: los que se originaron y se asentaron en zonas campesinas (rurales), y aquellos que se asentaron y originaron por lo común en capitales de estados o en ciudades de importancia (urbanos). La dinámica de estos movimientos fue sustancialmente distinta: los movimientos urbanos se nutrieron de cuadros juveniles con una sólida formación ideológica. En el medio rural, por el contrario, los lazos familiares actuaron como un poderoso factor cohesivo que suplió la falta de preparación ideológica. Los cuadros urbanos actuaron como células dotadas con un movimiento independiente clandestino; los cuadros rurales actuaron inmersos en un contexto solidario que los encubrió, protegió y proveyó de numerosos elementos humanos y estratégicos (cfr. Montemayor, 1997: 69-70). En ese orden de ideas, el EZLN asimiló la experiencia guerrillera de México y el trabajo de organización de masas en las zonas chiapanecas donde se asienta, en una especie de fusión de ambas tendencias. Diversas organizaciones agrarias locales realizaron trabajo político en ciertas zonas de Chiapas durante casi catorce años ininterrumpidos, al final de los cuales se establecieron los contingentes que formaron el EZLN ${ }^{3}$.

Ahora bien, en relación con la cuestión indígena y campesina, me interesa destacar una afirmación que puede parecer sorprendente por provenir de Octavio Paz, pero absolutamente pertinente para los propósitos de este trabajo. Paz apunta que, al referirse al movimiento zapatista original, del que el EZLN toma sus banderas y reivindicaciones, frente a la revolución progresista de 1910 y que continúa al liberalismo y al porfirismo, se da un movimiento de negación de esa revolución: la revuelta de los campesinos mexicanos en el sur, la cual luego sería derrotada e ideológicamente expropiada y desfigurada por los vencedores y el ejido concebido en términos predomi- nantemente burocráticos. Así, señala que si bien como sistema de producción el ejido es inferior a la agricultura capitalista, la importancia del ejido no reside en su capacidad de producir más sino que representa un espacio social y cultural para vivir mejor, para vivir de una manera diferente, más justa, armoniosa y libre que la actual. (cfr., Paz, 1987: 236-237).

La mayor parte de las revoluciones del siglo XX han sido como la revolución liberal mexicana del siglo XIX: tentativas por imponer esquemas geométricos sobre realidades vivas...Por más contradictorias que nos parezcan sus figuras y sus ideas, hay una continuidad entre Lorenzo de Zavala, Mora, Gómez Farías, Juárez, Ocampo, Bassols, Lombardo Toledano, etc., etc., Esa continuidad es el 'progresismo", la tentativa por 'modernizar' a México. Todos esos proyectos tienen en común el querer borrar, por decirlo así, la mancha, el pecado original de México: el haber nacido frente y contra el mundo moderno. Zapata es la negación de todo eso. Zapata está más allá de la controversia entre los liberales y los conservadores, los marxistas y los neocapitalistas: Zapata está antes y estará después. (Paz, 1987: 238).

Independientemente de las conclusiones a las que llega Paz en relación con el zapatismo de 1910 y luego el de 1994, el símil en el análisis me parece adecuado para ilustrar el surgimiento del EZLN, no como una simple insurrección guerrillera de corte marxista-leninista, sino como un movimiento que actualiza y le da rostro a un pasado que se creía superado, pero que además opta por las armas como consecuencia de las contradicciones generadas por la política modernizadora de las clases dirigentes, que no sólo los "negará" sino que evidenciará el enquistamiento del autoritarismo mexicano, a pesar de la supuesta modernidad política de la que se hablaba desde el poder: democracia, participación política, reforma del estado, apertura de los medios de comunicación, combate a la corrupción, etc., siguen siendo abstracciones sin contenido.

Cabría suponer, entonces, que la insurrección neozapatista, es la cara más visible de aquellos que niegan la nueva modernidad, impulsada en este caso por Salinas, es decir, los pobres extremos, los del mito genial (según la creatividad del secretario de Hacienda de esos años), los olvidados que están incluso fuera del sótano de la moderna pirámide nacional: los indígenas y los campesinos, una vez más. Son ellos los que reencarnan simbólicamente a Zapata, niegan la revolución económica impulsada por la administración Salinas y muestran al país que el primer mundo todavía está a varios millones de pobres de distancia.

3. Montemayor proporciona algunos nombres de organizaciones armadas que contaron con bases en diversas regiones de México: Movimiento Revolucionario del Pueblo, Partido de los Pobres, Asociación Cívica Nacional Revolucionaria, Comando Urbano Lacandones 'Patria Nueva', Frente Urbano Zapatista, Partido Revolucionario Obrero Clandestino Unión del Pueblo, Unión Campesina Independiente, Movimiento 23 de Septiembre, Liga Comunista 23 de Septiembre, Liga Comunista Espartaco, Frente Revolucionario del Pueblo, Fuerzas Revolucionarias Armadas del Pueblo y Fuerzas Armadas de Liberación. 
Así, el impacto del EZLN es decisivo en otras latitudes en la medida en que pondrá en primer plano la discusión de los contenidos de varios conceptos centrales. El que Marcos se haya convertido en una especie de portavoz de la lucha mundial en contra del neoliberalismo podría parecer un exceso como lo denuncian La Grange y Rico, pero lo que no lo es, es que el EZLN haya subrayado las enormes contradicciones que ese modelo supone. En efecto, el neoliberalismo acentuó en México y en los países en los que se aplicó, las desigualdades sociales y económicas, por la vía del desempleo masivo en aras de la competitividad de las empresas, los recortes presupuestales del gasto público en áreas fundamentales como la educación y la seguridad social, entre otros fenómenos. En esa medida, puede decirse que el movimiento del EZLN es un movimiento tradicional y moderno también, a la vez que una expresión en contra y a favor de la llamada globalización. Al respecto, tomemos en consideración que el neoliberalismo constituye un modelo que sirve de fundamento a un cierto proceso de globalización, cuyas manifestaciones más evidentes se dan en el campo económico, financiero y de los medios de comunicación, y con mucho menos notoriedad en lo político-que no sea la cuestión de los derechos humanos- cultural y social, pero las respuestas en su contra son igualmente globales.

Es cierto que muchas de las carencias en México y en otros países son rezagos ancestrales, pero no es menos cierto que la aplicación de esas políticas ha llevado a un grado extremo la pobreza y la marginación. De acuerdo con Eric Hobsbawm casi dos tercios de la población mundial han obtenido muy poco o ningún beneficio del rápido crecimiento económico. (Rodríguez Araujo, 1996: 118).

Así, podría argumentarse que desde el poder se promueve un cierto modelo de globalización que favorece el funcionamiento del mercado libre así como la promoción de la democracia y los derechos humanos, el combate al narcotráfico, al terrorismo y cuanto mal global vaya presentándose. Empero, de manera paralela a dicho proceso se han generado otras tendencias globales que parecieran menos notorias, como señalé anteriormente, pero con un impacto fundamental en la conciencia, denominémosla, global.

Apunta Michel Husson que en el capitalismo contemporáneo se inscribe la noción de desarrollo desigual y combinado. "La dialéctica fraccionamiento/integración aparece en efecto como el movimiento principal de la economía mundial... pero ha perdido su capacidad de extender a profundidad su lógica, y funciona como una enorme máquina de exclusión: más que asimilar a su lógica a las capas sociales y las zonas geográficas, ejerce un aislamiento sistemático y rechaza todo lo que no tiene éxito para integrarse en su lógica." (Husson en Rodríguez Araujo, 1996: 119).

Me parece, sin embargo, que a pesar de la denuncia de los síntomas más claros de la denominada globalización (con el neoliberalismo en la cima de las mismas) no existe un entendimiento adecuado del proceso. Cabe subrayar que al lado de los aspectos que interesa promover a las clases dirigentes, existe otro proceso igualmente global pero que no ha sido analizado suficientemente en virtud de su aparente novedad. Roland Robertson arroja luces sobre este aspecto. Señala que las tendencias hacia la unidad del mundo son inexorables y que en esa medida el concepto de globalización se refiere tanto a la compresión del mundo como a la intensificación de la conciencia de éste como un todo, lo cual empíricamente está en línea con la creciente interdependencia global y la concientización de lo global.

De tal manera, la globalización está íntimamente ligada al desarrollo y naturaleza de la modernidad y por eso se refiere de manera clara a ese problema. No obstante, la globalización no puede ser entendida simplemente como un aspecto del proyecto occidental de modernidad, como lo sugiere la realidad mexicana, entre otras). Lo relativamente novedoso del concepto, es precisamente el objeto principal de discusión y no los procesos y acciones a los que apunta el concepto actualmente, las cuales se han desarrollado por siglos, siendo el estado nacional uno de los mejores ejemplos.

Roland Robertson propone un modelo analítico, que desde una perspectiva cultural, se aboca al estudio de la globalización, con énfasis en cuatro actores y en las relaciones que se establecen entre ellos: las sociedades nacionales, el sistema internacional, los individuos y los grupos étnicos, con el propósito de centrarse en el estudio de las maneras y procesos en los que perciben la globalidad, en relación con la estructura básica de ese campo, el cual, subraya, está delineado por dichos actores y las relaciones que se establecen entre ellos. En esa medida puede observarse cómo los individuos, los movimientos y otros actores perciben y construyen el orden (desorden) del mundo en diversos modos.

Efectivamente, este modelo de globalización intenta dar sentido analítico e interpretativo a las maneras en que los actores, colectiva o individualmente, conciben el mundo como un todo, incluyendo los intentos por negar que el mundo es uno. De ahí que puedan darse respuestas globales sin perder de vista lo local, como cabría suponer con el EZLN, no en cuanto a la utilización de las armas sino en torno a los conceptos a los que me referí en las hipóstesis.

Es cierto que existen impedimentos para que los actores sociales se perciban a sí mismos como parte de la historia mundial y del futuro global, pero la globalización, como proceso cultural, incluiría, igualmente, la difusión de las identidades, sin perder de vista la dinámica del capitalismo. Por ello, en un mundo crecientemente interdependiente, se vigoriza la conciencia civilizacional, social, étnica, regional e individual. Así, desde una perspectiva amplia puede argumentarse que la globalización, en términos culturales, implica la reafirmación de los particularismos. Un síntoma evidente de ello, es que las sociedad nacional, entendida como concepto homogéneo se está destruyendo y ello a pesar del resurgimiento de nacionalismos en algunas partes del orbe. Por esa y otras razones, observamos una creciente tendencia por escribir la historia mundial, nacional, local, con respecto a las voces no escuchadas.

De tal suerte, no parece sostenible el argumento de que el mundo sólo puede ser entendido en términos del proceso particular de Occidentalización. Analistas como, Rodríguez Araujo, sostienen que la "lucha contra el neoliberalis- 
mo es la lucha contra la continuidad del proceso de mundialización de la economía y, por lo tanto, en favor de la humanidad en su conjunto. Esta lucha, debido a que el neoliberalismo es mundial y la lógica de la mundialización de la economía es también mundial... deberá ser popular e internacional por su contenido, nacional por su forma." (Rodríguez Araujo, 1996: 127).

En ese contexto, el problema de las identidades y la democracia no solamente tiene vigencia sino una enorme importancia. Recordemos que la guerra entre el ejército mexicano y el EZLN, propiamente dicha, no duró más que algunos días, del 1 al 12 de enero de 1994. Desde entonces los zapatistas, muy lejos de contemplar la toma del poder como objetivo de su lucha armada, con base en las demandas de la denominada sociedad civil buscaron incorporar a sus objetivos, la lucha por la democracia, sin abandonar una de las banderas originales más importantes, es decir, la tierra, símbolo máximo de la identidad campesina e indígena. En subsiguientes comunicados convocarían a la Convención Nacional Democrática (aunque no se tradujo en resultados concretos), el Encuentro Intergaláctico, etc. Así, la naturaleza del movimiento del EZLN aparece más compleja que los que sus antecedentes guerrilleros podrían sugerir; a las contradicciones que se originan en los conflictos religiosos y agrarios, suman la lucha por la reafirmación de los particularismos, la búsqueda de una democracia abierta en la que participen todos los actores sociales, que tome en cuenta las exigencias éticas y las identidades. Se mantienen armados, recurren a la negociación, a las alianzas, al protagonismo en los medios de comunicación modernos, etc.

Desde luego que no se justifica la violencia, aún cuando sea por parte de aquellos que "agotada toda otra vía para hacer escuchar sus aspiraciones y sus demandas, forman un movimiento político civil cuyo propósito no es la toma del poder." (Le Bot, 1997: 21) La insurrección zapatista tiene respaldo en México y en el mundo pues no es sólo un problema local o minoritario y ha puesto en tela de juicio cuestiones políticas, culturales, religiosas, etc., que son fundamentales en todas las sociedades. En esa medida, como lo sugiere Le Bot, el zapatismo no supone un repliegue comunitario ni un nacionalismo cerrado, en la medida que trata de articular las experiencias de comunidades heterogéneas, divididas y abiertas, la democracia nacional y el proyecto de una sociedad de sujetos, individuales y colectivos, que se reconozcan y puedan respetarse en su diversidad, en su lucha por un mundo donde quepan muchos mundos. El actor zapatista es étnico, nacional y universal. Se quiere mexicano pero sin dejar de ser indígena, quiere un México donde pueda ser reconocido y escuchado. Esa universalidad debe entenderse de dos maneras. Primero en un sentido ético clásico: el indígena, discriminado, siempre en minoría, humillado, es portador de la reivindicación igualitaria de todo ser humano. Pero también debe entenderse, en una forma más rica y positiva, en la perspectiva de un sujeto que combina en su afirmación el sentido ético y étnico, que encuentra lo universal en lo particular. El zapatismo es portador de una triple exigencia -política, ética y de afirmación del sujeto- que resume en su fórmula predilecta: democracia, justicia, libertad y dignidad (Le Bot, 1997: 22).

\section{Consideraciones finales}

Si bien parecería absurdo pensar que el gobierno aceptaría llevar adelante una política tendiente a la autoinmolación del régimen que le sustenta, no es exagerado sugerir que Chiapas brinda una oportunidad para impulsar una transición política en el país, sentando las bases de una democracia genuina a partir del reconocimiento de la pluralidad cultural mexicana, cuya veta más rica es la indígena, pero no el indígena del museo o de discurso, sino de aquel que representa el patrimonio vivo de la nación, liquidando las concepciones racistas y discriminatorias que comienzan con ellos, pero que permean a toda la sociedad mexicana. En ese esfuerzo habría que abolir de una vez y para siempre el recurso de la violencia, transformar a partir de la construcción de ese sistema político democrático, auténtico, no sólo a los reformadores armados, sino terminar con la corrupción, la desigualdad y la impunidad.

Como seguramente lo sugeriría Guillermo Bonfil Batalla, deberíamos intentar dejar de ver a México desde Occidente para aprender a hacer lo contrario, alentando los procesos y los cauces para que el México profundo surja por sobre el México imaginario. Por tal motivo, no se trata de una simple inyección de recursos para "combatir" la pobreza en la región de Chiapas o la sustitución de unos caciques por otros, de la complacencia con el gobierno. Se trata de resolver la problemática indígena, chiapaneca en primera instancia, desde luego, pero de acabar, asimismo, con el autoritarismo, el paternalismo y la corrupción que afectan a todo el país. No debe olvidarse que el conflicto chiapaneco ocupa un espacio muy importante en la conciencia nacional. Chiapas constituye un mosaico de pluralidad cultural, social, política, étnica, económica, religiosa, y en esa medida es una especie de laboratorio político, del que en buena medida depende el futuro del país en términos de la convivencia política, social, económica y cultural. De no adoptarse una solución amplia y progresiva que comience con la puesta en práctica de los Acuerdos de San Andrés Larraínzar, la apatía, el desgaste y la indiferencia como consecuencia de la prolongación del conflicto perjudicará no sólo al EZLN sino al gobierno mismo y a la sociedad en su conjunto.

Es cierto que un proceso de negociación de este tipo lleva varios años como los muestran los casos de El Salvador y Guatemala, pero además de que esa explicación pareciera no ser suficiente, lo más preocupante es que tras cuatro años de conflicto se siga insistiendo en la difusión ante la opinión pública, del movimiento zapatista como una guerrilla de estructura y banderas anacrónicas, tendencia que se fortaleció luego de las "revelaciones" del subcomandante David, que documentan Rico y La Grange en su libro, y que habían permitido a las autoridades mexicanas develar la identidad de Marcos y el origen del EZLN en las Fuerzas de Liberación Nacional (FLN), que se pensaba habían sido desmanteladas completamente en la década de los setenta. No es sostenible el argumento, más que para 
una solución de fuerza, de que el EZLN no es sino un producto de la megalomanía de dos personajes claves en la región: el subcomandante Marcos, quien intenta revivir en su persona el mito del Che Guevara y que ha desarrollado un sentido de la puesta en escena, que aunado a su pasamontañas y sus comunicados ha seducido a numerosos intelectuales, y del obispo Samuel Ruiz, quien, según esa interpretación, hace todo cuanto le es posible (sobre todo la complicidad con el EZLN) para obtener el premio Nobel de la Paz. No debe sorprender a esta alturas que un blanco, como reza la parafernalia oficial, encabece la rebelión indígena, pues bastaría con una revisión de esa parte de la historia mexicana para constatar que no se trata simplemente de un complot. En buena medida ese mestizo, ese blanco, que tiene varios nombres a lo largo de la historia, ha jugado el papel de puente de interlocución entre dos mundos aparentemente irreconciliables.

Al respecto, Montemayor se pregunta si no sería más exacto tratar de explicar las insurrecciones mediante la miseria, el hambre y la opresión política, ya que solemos olvidar que los combatientes de ambos bandos no son solamente enemigos, cabecillas, provocadores, instigadores o defensores que enarbolan una idea moral o patriótica, sino que poseen razones humanas.

Primero, porque el país ha vivido, sin saberlo quizás la mayoría de los mexicanos, en una lucha guerrillera casi ininterrumpida a lo largo de por lo menos treinta años. Segundo, porque la primera reacción oficial ante un grupo guerrillero no es de orden militar o policiaco, sino la tajante descalificación de su naturaleza: se le acusa de grupo terrorista o se le descalifica como gavilla de bandidos o delincuentes comunes. Tercero, porque no desaparece la lucha armada en México a pesar del desmantelamiento de grupos guerrilleros enteros y de la captura de sus dirigentes. Finalmente, porque si ciertas condiciones sociales y económicas no cambian tampoco desaparecerán los grupos armados o guerrilleros que luchan contra esas condiciones. (Montemayor, 1997: 15).

Así, sería ilusorio creer que los indígenas apoyaron la rebelión por su inocencia y analfabetismo, o porque alguien les hubiera leído un panfleto ideológico o los hubieran amenazado o reclutado. La disposición de comunidades enteras para apoyar un movimiento así, al menos con el silencio, la provocan y explican agitadores sociales muy evidentes en Chiapas: el hambre, el despojo, la represión, la cerrazón de autoridades políticas y judiciales, la presión de ganaderos y terratenientes" (Montemayor, 1997: 62).

La lucha por la tierra es el origen principal de desequilibrio social en ese estado. El despojo agrario y la miseria extrema son los dos aspectos fundamentales de ese desequilibrio en Chiapas. La tierra para las comunidades indígenas no es sólo un asunto de productividad y competitividad: es la razón esencial de su conocimiento de la vida, que las une al mundo invisible y al mundo visible, que las une con la comunidad ancestral de hombres y dioses, que contiene la raíz de sus valores éticos, económicos, familia- res; que es el soporte de su cultura. Por ella siempre han sido capaces de dar la vida. Por ella son capaces de apoyar, cuidar, encubrir o sumarse a un movimiento armado que osa enfrentarse al gobierno y al ejército nacional (Montemayor, 1997: 62-63).

Pero además en función de lo que demandan y de la naturaleza misma del EZLN, la guerrilla pone de manifiesto el problema de las identidades mexicanas, la democracia y la equidad de cara a la globalización. El movimiento zapatista subraya la necesidad de reimaginar la manera en que la nación mexicana, como comunidad imaginaria, está cimentada para hacer de ella un espacio equitativo y justo para todos sus habitantes. Requiere construir una democracia con varios adjetivos para que sea una democracia genuina y tenga la credibilidad y la confianza de los mexicanos, como por ejemplo: la alternancia en el poder, la división efectiva de los poderes y la apertura de los medios de comunicación. No se trata de concesiones del poder sino de asegurar la participación de los individuos, los grupos y las comunidades en la planeación y diseño del país y de su futuro. Para ello, se requiere trastocar los cimientos del edificio político mexicano para darle otra estructura: una que sea más abierta y facilite la participación permanente de la sociedad en su conjunto.

No es aceptable la prolongación del conflicto, no sólo a riesgo de tener que enfrentar los problemas secundarios que crea la paz armada en Chiapas como la proliferación de la desinformación, la "complicidad” de Samuel Ruiz para no perder la oportunidad de ganar un premio internacional, el "mesianismo" de Marcos y todos aquellos males que denuncian La Grange y Rico, sino mucho más importante perder la oportunidad de avanzar en la construcción de la democracia genuina.

Es necesario reconocer que el conflicto chiapaneco tiene múltiples facetas además de la violencia: la cultural y religiosa, la de la pobreza lacerante y el conflicto por la tierra, la del autoritarismo político y la corrupción. Los esfuerzos visibles de la negociación por parte del gobierno federal a través de la dotación de energía eléctrica, drenaje, caminos, educación o servicios de salud sólo resolverán una parte del rezago económico indígena y por lo mismo, no son una solución integral. Los conflictos agrarios como se intentó demostrar en este trabajo son fundamentales y requieren de un cese radical en la expansión y actitud agresiva de los terratenientes, ganaderos y políticos en Chiapas. Adicionalmente, se requiere desmantelar las redes clientelares y de corrupción política, pero, insisto, no cambiar simplemente a los antiguos caciques por unos nuevos con más voluntad de arreglar las cosas, pues de otra suerte continuará el círculo vicioso.

Como lo anota Montemayor, México ha tenido y seguirá teniendo la insurrección guerrillera como natural, ya sea social, política, indígena, agraria, que avisa que el país debe cambiar o que no es aún lo que debe ser. El EZLN cumplió exigiendo de la sociedad entera un cambio y poniendo en el primer plano las preocupaciones que interesan a todos los mexicanos. La tarea actual se refiere a la lucha por transformar los objetivos políticos de esa insurrección en logros concretos para todos. 


\section{Bibliografía}

Anderson Benedict (1991), Imagined Communities, (Verso, London \& New York,), 224 p.

Bonfil Batalla Guillermo (1992), Pensar Nuestra Cultura, (Alianza Editorial, México), 172 p.

MONTEMAYOR Carlos (1997), Cbiapas. La rebelión indígena de México, (Joaquín Mortiz, México,) 191 p.

La Grange Bertrand y Rico Maite (1998), Marcos, la genial impostura, (Nuevo Siglo Aguilar, México), $472 \mathrm{p}$.

LE Bot Yvon (1997), El sueño zapatista, (Plaza\&Janés, Barcelona), $376 \mathrm{p}$.

Paz Octavio (1987), México en la Obra de Octavio Paz, T. I, (F.C.E., México), 766 p.

PUENTE ORDORICA Guillermo(1994), Cultural Colonialism and the Nation-State, tesis de maestría (University of Leeds, Leeds), 85 p.

Puente Ordorica Guillermo \& SÁnchez Colín Víctor (1991), La Cultura Nacional: base de la Democracia y Soberania en México, tesis de licenciatura (UNAM, México), $290 \mathrm{p}$.

ROBERTSON Roland (1992), Globalization, (Sage, London), $211 \mathrm{p}$.

ROCKER Rudolf (1978), Nationalism and Culture (The Croixside Press, Minnesota), 610 p.

Tello Díaz Carlos (1995), La rebelión de las Cañadas (Cal y Arena, México), 247 p.

\section{Hemerografía}

AzNÁREZ Juan J. (1998), “Chiapas, odio y sangre”, El País, Madrid, 19 de abril, pp. 14-15.

CASAs Pérez M. a de la Luz (1996), "Democratización y cultura en México. Modernización, identidad nacional y resistencia cultural", Revista Mexicana de Ciencias Políticas y Sociales, No. 166, México, pp. 71-86.

ENFOQUE (1998), "Ex Comisionados para la paz en Chiapas”, Reforma, No. 209, México, 18 de enero, pp. 4-9.

PUENTE ORDORICA Guillermo (1996), "La percepción de la dimensión cultural en la política exterior de México", El Financiero, 13 de agosto, p. 24.

Rodríguez Araujo Octavio (1996), "Política y Neoliberalismo", Revista Mexicana de Ciencias Políticas y Sociales, No. 166, pp. 113-132.

\section{Otras fuentes}

En Internet www. ezln. org

Declaración de la Selva Lacandona (1994), 1 de enero.

Segunda Declaración de la Selva Lacandona (1994), 10 de junio.

Tercera Declaración de la Selva Lacandona (1995), enero.

Cuarta Declaración de la Selva Lacandona (1996), 1 de enero.

Primera Declaración de La Realidad (1996), enero.

Segunda Declaración de La Realidad (1996), agosto.

Palabras del Ejército Zapatista de Liberación Nacional en el acto de clausura del Primer Encuentro Intercontinental por la Humanidad y contra el Neoliberalismo (1996), 3 de agosto.
Comunicado del Comandante Zebedeo sobre incendios en la zona de conflicto, Ejército Zapatista de Liberación Nacional (1998) enero.

Comunicado del Comité Clandestino Revolucionarios Indígena, Comandancia General del Ejército Zapatista de Liberación Nacional al pueblo de México (1998), 3 de enero.

Comunicado del Comité Clandestino Revolucionarios Indígena, Comandancia General del Ejército Zapatista de Liberación Nacional al pueblo de México (1998), 4 de enero.

Comunicado del Ejército Zapatista de Liberación Nacional a la sociedad civil internacional (1998), 5 de enero.

Comunicado del Comité Clandestino Revolucionario Indígena, Comandancia General del Ejército Zapatista de Liberación Nacional al pueblo de México (1998), 5 de enero.

Comunicado de Marcos, Ejército Zapatista de Liberación Nacional a la prensa nacional e internacional (1998).

Comunicado del Comité Clandestino Revolucionario Indígena, Comandancia General del Ejército Zapatista de Liberación Nacional a la opinión pública, los pueblos y gobiernos del mundo, la prensa nacional e internacional, los organismos de derechos humanos nacionales e internacionales y la CONAI (1998), 8 de enero.

Comunicado de Marcos, Comité Clandestino Revolucionario Indígena, Comandancia General del Ejército Zapatista de Liberación Nacional a la prensa nacional e internacional (1998), 9 de enero.

Comunicado de Marcos, Comité Clandestino Revolucionario Indígena, Comandancia General del Ejército Zapatista de Liberación Nacional a la sociedad civil nacional e internacional (1998), enero.

Comunicado de Marcos, Comité Clandestino Revolucionario Indígena, Comandancia General del Ejército Zapatista de Liberación Nacional a la CONAI (1998), 14 de enero.

Comunicado de Marcos, Comité Clandestino Revolucionario Indígena, Comandancia General del Ejército Zapatista de Liberación Nacional al Planeta Tierra (1998), enero.

Comunicado del Comité Clandestino Revolucionario Indígena, Comandancia General del Ejército Zapatista de Liberación Nacional a la sociedad civil nacional e internacional y a las organizaciones políticas y sociales honestas de México y el Mundo (1998), 29 de enero.

Comunicado de Marcos, Comité Clandestino Revolucionario Indígena, Comandancia General del Ejército Zapatista de Liberación Nacional a la Comisión Civil Internacional de Observación por los Derechos Humanos (1998), febrero.

Subcomandante Marcos (1998), "Un periscopio invertido (o la memoria, una llave enterrada)", febrero.

Subcomandante Marcos (1998), "Tres mesas para la cena de fin de siglo", febrero.

Subcomandante Marcos (1998), "La mesa de San Andrés entre los Olvidos de Arriba y la Memoria de Abajo".

Comunicado del Ejército Zapatista de Liberación Nacional (1998) a la Comisión de Concordia y Pacificación, 1 de marzo 


\section{RESUMEN}

El autor sostiene que el movimiento insurgente encabezado por el Ejército Zapatista de Liberación Nacional (EZLN), es un movimiento tradicional y moderno a la vez, tanto por su propia naturaleza como por las demandas que enarbola: democracia, justicia, libertad y dignidad indígena. El zapatismo ha tenido un impacto decisivo en México y fuera de ese país, ya que ha puesto en primer plano, la discusión de cuestiones políticas, culturales y sociales fundamentales para todas las sociedades. Sin embargo, las negociaciones entre el gobierno mexicano y el movimiento zapatista, no han desembocado en una solución definitiva a pesar de la firma, en 1996, de los Acuerdos de San Andrés. Ello, en virtud de la falta de voluntad política del gobierno, que se ha reflejado en su actitud contradictoria, pero sobre todo porque no posee la capacidad estructural para incorporar las demandas de dicho movimiento, que toca las fibras neurálgicas del sistema político mexicano, autoritario y cerrado. Empero, para el autor la asimilación del zapatismo representaría un paso definitivo en la transición política que facilitaría la construcción de una democracia genuina.

Palabras clave: EZLN, indígenas, pobreza, tierras, gobierno, México, acuerdos, paz.

\section{ABSTRACT}

The guerrilla movement leaded by the Ejército Zapatista de Liberación Nacional (EZLN), by its own nature and the claims it has raised: democracy, justice, freedom and indigenous dignity, is at the same time a traditional and a modern movement. The zapatismo has had a big impact in Mexico and out of the country, due to the fact that it has brought to the main scene the discussion of political, cultural and social affairs central to all societies. However, the negotiations between the Mexican government and the EZLN has not produced a final solution of the conflict itself, notwithstanding the signature, in 1996, of the agreements of San Andrés. The former due to the government's lack of political will, but mainly because the Mexican political system, still authoritarian, do not have the structural capacity to incorporate the zapatista movement's political claims. The author suggests notwithstanding, the incorporation of the zapatismo as a definitive step towards a political transition that will enable to build a genuine democratic system.

Key words: EZLN, indigenous, poverty, Land, government, México, Peace’s Agreements.

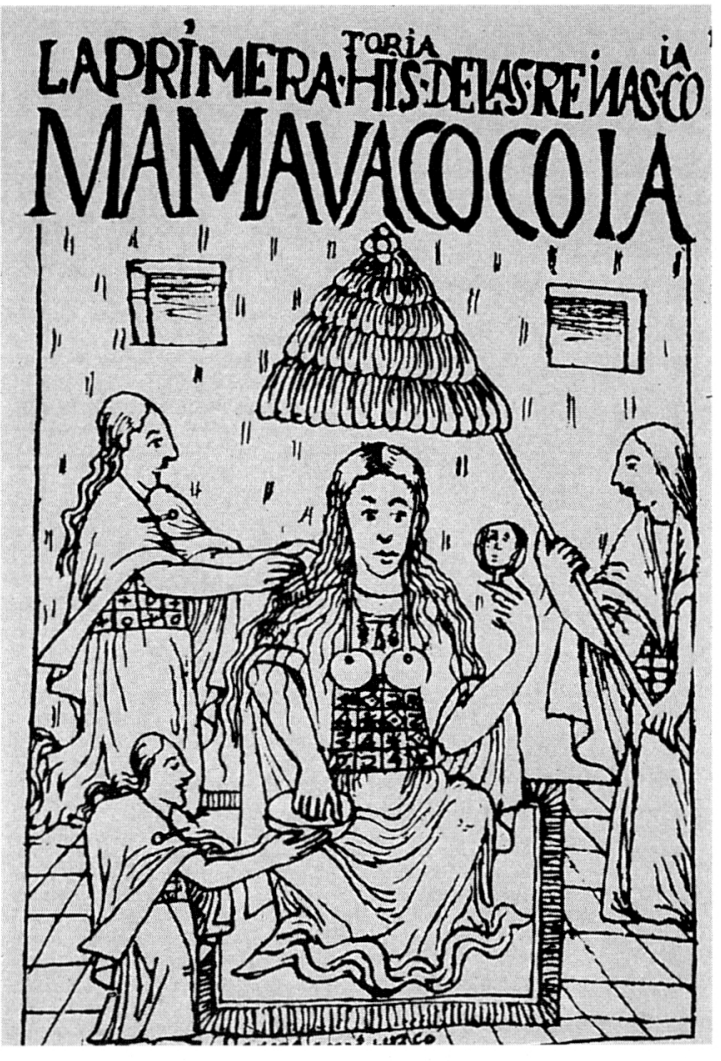

Mama Huaco 